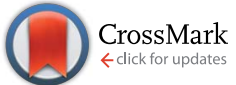

Cite this: Chem. Sci., 2015, 6, 2506

Received 21st December 2014 Accepted 13th February 2015

DOI: $10.1039 / c 4 s c 03966 a$

www.rsc.org/chemicalscience

\title{
Extending $N$-heterocyclic carbene ligands into the third dimension: a new type of hybrid phosphazane/NHC system $\uparrow+$
}

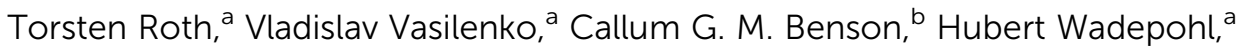 \\ Dominic S. Wright ${ }^{\star b}$ and Lutz H. Gade*a
}

A simple, "click" synthetic approach to a new type of hybrid phosph(III)azane/NHC system is described. The presence of the phosphazane $\mathrm{P}_{2} \mathrm{~N}_{2}$ ring unit, with $\mathrm{P}$ atoms flanking the $\mathrm{NCN}$ fragment and with this ring perpendicular to the binding site of the $\mathrm{NHC}$, provides unique opportunities for modifying the electronic and steric character of these carbenes.

\section{Introduction}

$N$-heterocyclic carbenes have been successfully established as versatile ligands in coordination chemistry, as powerful ancillary ligands in catalysis, as organocatalysts, and for an increasing number of other applications. ${ }^{1-6}$ In view of these applications the ability to vary the steric and electronic character of these ligands systematically, using simple modular synthetic routes, is a central theme in this area. In recent years a range of approaches to modify their $\sigma$-donor $/ \pi$-acceptor and coordination properties have been implemented, ${ }^{7}$ for instance different ring sizes of the backbone resulting in different $N C N$ angles, ${ }^{8}$ variation of the heteroatoms adjacent to carbon, ${ }^{9}$ abnormal and remote carbenes, ${ }^{10}$ acyclic carbenes, ${ }^{11}$ anti-Bredt NHCs, ${ }^{12}$ push-pull carbenes, ${ }^{13}$ redox-switchable $\mathrm{NHCs}^{14}$ or even cyclophane-derived carbenes. ${ }^{15}$ A less explored approach relies on NHCs comprising "inorganic" or organometallic fragments in their ligand backbones (relevant examples shown in Fig. 1). ${ }^{\mathbf{1 6}}$

$$
\text { Grubbs } \quad \begin{array}{ccc}
\text { Bertrand } \\
\text { dipp- }
\end{array}
$$

Fig. 1 Selection of "inorganic" carbenes.

\footnotetext{
${ }^{a}$ Anorganisch-Chemisches Institut, Universität Heidelberg, Im Neuenheimer Feld 270, 69120 Heidelberg, Germany. E-mail: lutz.gade@uni-heidelberg.de

${ }^{b}$ Chemistry Department, Cambridge University, Lensfield Road, Cambridge, CB2 1EW, UK. E-mail:dsw1000@cam.ac.uk

$\dagger$ Electronic supplementary information (ESI) available: Methods and additional data. CCDC 1040123 1040125-1040128. For ESI and crystallographic data in CIF or other electronic format see DOI: $10.1039 / \mathrm{c} 4 \mathrm{sc03966a}$

\$ Dedicated to Professor Manfred Scheer on the occasion of his 60th birthday.
}

This is, however, potentially a very powerful approach to ligand modification since introducing flanking electron-donating (e.g., P) or electron-accepting (e.g., B) main group atoms should have a profound effect on the acceptor or donor ability of the $N C N$ unit.

In contrast, much less effort has been dedicated to the systematic development of NHC ligands with unusual and improved spatial characteristics. ${ }^{17}$ Most approaches focussed on the introduction of various bulky substituents in the wingtip position. Although a variety of backbone structures containing heteroatoms have been reported in recent years NHCs are still regarded as essentially two-dimensional ancillary ligands. Even though NHCs have proven to be superior to phosphine ligands in several respects, the latter are often chosen preferentially due to their three-dimensional shape, which is of relevance inter alia in enantioselective homogenous catalysis. ${ }^{18}$

Herein, we present a conceptually new approach for the design of the steric properties of NHC-ligands, which have so far only been perceived as essentially flat donor entities. Our system constitutes the first example of a three-dimensional arrangement encompassing the central $N C N$-unit that allows for straightforward control of the steric properties of the top and bottom hemispheres of the widespread NHC-ligand framework. This is achieved by a unique inorganic backbone moiety
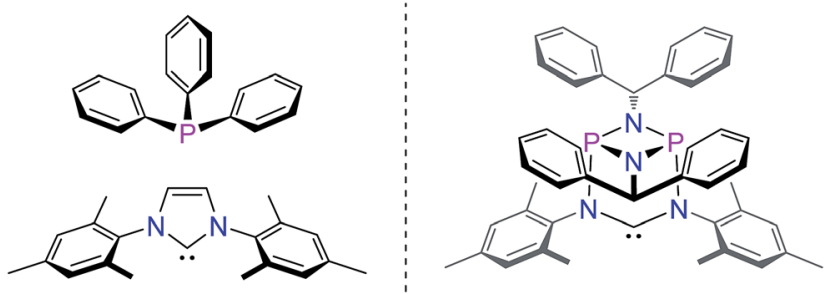

Fig. 2 Spatial characteristics of phosphines, NHCs (left) and the targeted 3-dimensional hybrid phosphazane/NHC ligand (right). 
consisting of a cyclophosphazane $\mathrm{P}_{2} \mathrm{~N}_{2}$-unit that is orthogonally attached to the $N C N$-fragment (Fig. 2).

Stemming from our interest in the modular synthesis of cyclophosph(III)azane ligands for catalysis, ${ }^{19}$ we have begun to explore the possibility of developing a simple "click-type" approach to ambidentate ${ }^{20}$ hybrid phosphazane/NHC ligands as shown in Fig. 2. We reasoned that the presence of the $\mathrm{P}_{2} \mathrm{~N}_{2}$ ring unit (perpendicular and adjacent to the $N C N$-fragment) would provide a unique strategy for modifying the electronic and spatial characteristics of the NHC system.

\section{Results}

The preparation of the new ligand system starts from simple $\mathrm{Me}_{3}$ Si-protected diarylformamidines and dichloro-cyclophosphazanes, both of which are readily accessible on a multigram scale. Condensation of the two components and subsequent ring-closure using $\mathrm{Et}_{3} \mathrm{Si}$-OTf furnishes cationic azolium salts, ${ }^{21}$ a key example of which is 2 (Fig. 3). The solid state structure of 2 confirms the bicyclic cage structure in which the $N C N$-unit bridges the $\mathrm{P}_{2} \mathrm{~N}_{2}$-ring. The $\mathrm{P}_{2} \mathrm{~N}_{2}$ moiety and its substituents are orthogonal to the carbene plane, thus effectively shrouding the posterior of the carbene system.

Notably, quantitative formation of carbene species 3 was observed upon addition of KHMDS to 2, exhibiting a single ${ }^{31} \mathrm{P}$ NMR signal (197 ppm) and a characteristic ${ }^{13} \mathrm{C}$ NMR resonance at $260 \mathrm{ppm}$, corresponding to its carbene carbon atom, in the in situ recorded spectrum (Scheme 1). Although carbene species 3 is stable in solution for several hours, attempts to isolate the free carbene invariably led to partial decomposition.

We then turned to probing the reactivity of carbene 3 employing Lewis-acidic metal-fragments. Deprotonation of 2
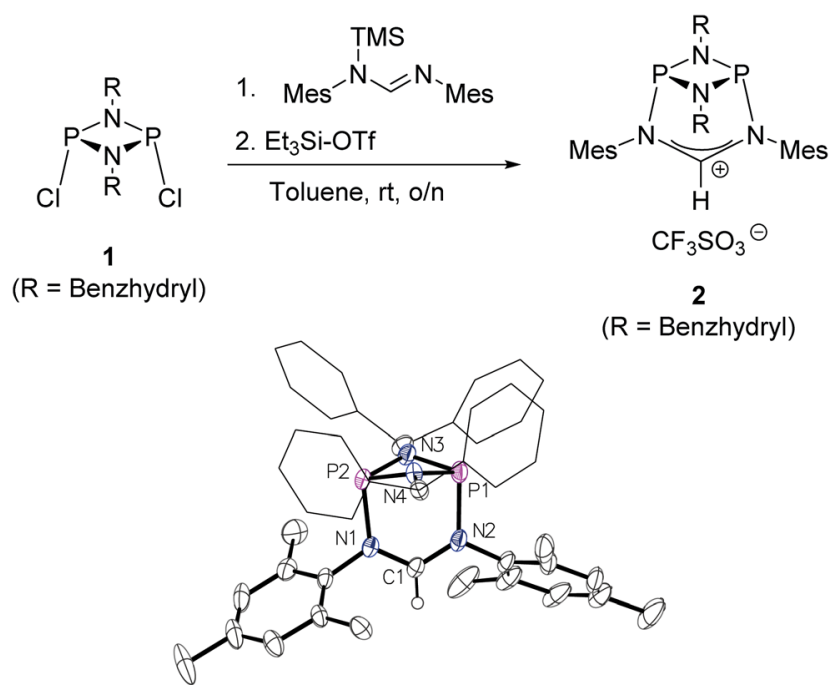

2

$(\mathrm{R}=$ Benzhydryl)

Fig. 3 Top: one-pot access to the cationic cyclophosphazane cage compound 2. Bottom: molecular structure of 2, thermal ellipsoids set at the $50 \%$ probability level. $\mathrm{H}$-atoms except $\mathrm{H}(1)$ and the trifluoromethanesulfonate counterion have been omitted for clarity. Phenyl rings of the benzhydryl substituents are drawn as wireframes. Selected bond lengths $[\AA]]$ and angles $\left[^{\circ}\right]$ : P1-N2 1.837(3), P1-N3 1.704(3), N1-C1 1.323(4), N2-C1-N1 122.7(3).
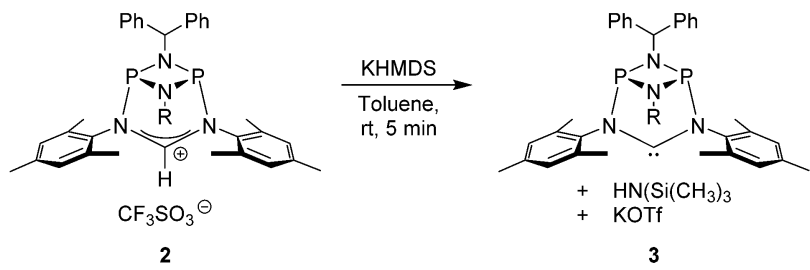

Scheme 1 In situ generation of carbene 4

and subsequent addition of half an equivalent of $[\operatorname{Ir}(\operatorname{cod}) \mathrm{Cl}]_{2}$ led to quantitative formation of the robust ${ }^{22}$ NHC-metal complex 4 (Scheme 2, Fig. 4, left). To classify the electron-donor properties of the carbene unit we determined the electrochemical characteristics of $\mathbf{4}$ and the TEP (Tolman Electronic Parameter) ${ }^{23}$ of the $\left[\mathrm{Ir}(\mathrm{CO})_{2} \mathrm{Cl}\right]$ carbene complex 5 (for the solid-state structure of 5 see ESI $\dagger$ ).

The IR spectrum of $\mathbf{5}$ displays CO stretching vibrations at $1976 \mathrm{~cm}^{-1}$ and $2060 \mathrm{~cm}^{-1}$ with a calculated ${ }^{24}$ TEP value of 2045 $\mathrm{cm}^{-1}$ representing a two-electron donor capacity comparable to other six-membered "inorganic" carbenes (Fig. 1, Bertrand et al.). ${ }^{16 c}$ Moreover, the cyclic voltammogram of 4 features a single quasi-reversible oxidation step $\left(E_{1 / 2}=+0.653 \mathrm{~V}, \Delta E=159\right.$ $\mathrm{mV}){ }^{25}$ suggesting that the cyclophosphazane carbene is a powerful electron donor ligand. The strong $\sigma$-donor character of 3 is consistent with the presence of the donor-P atoms adjacent to the $N C N$-unit.

One of the most notable features of the solid-state structures of the iridium complexes $\mathbf{4}$ and $\mathbf{5}$ is the presence of two conical binding pockets of local $C_{3}$ symmetry around the uncoordinated phosphorus atoms, the borders of these cavities being defined by the benzhydryl phenyl and mesityl rings (Fig. 4, right).

This led us to repeat the complexation reaction used in the formation of 4 employing 1.5 equivalents $[\operatorname{Ir}(\operatorname{cod}) \mathrm{Cl}]_{2}$. Surprisingly, the ${ }^{31} \mathrm{P}$ NMR spectrum showed two doublets $\left(J_{\mathrm{P}-\mathrm{P}}=30\right.$ $\mathrm{Hz}$ ), suggesting a dimetallic complex in which there is unsymmetrical coordination of the $\mathrm{P}_{2} \mathrm{~N}_{2}$ ring. Even after the addition of an excess of the iridium precursor no further species were detected by ${ }^{31} \mathrm{P}$ NMR, indicating that the lone pair of the second phosphorus atom is not accessible for coordination. The solid-

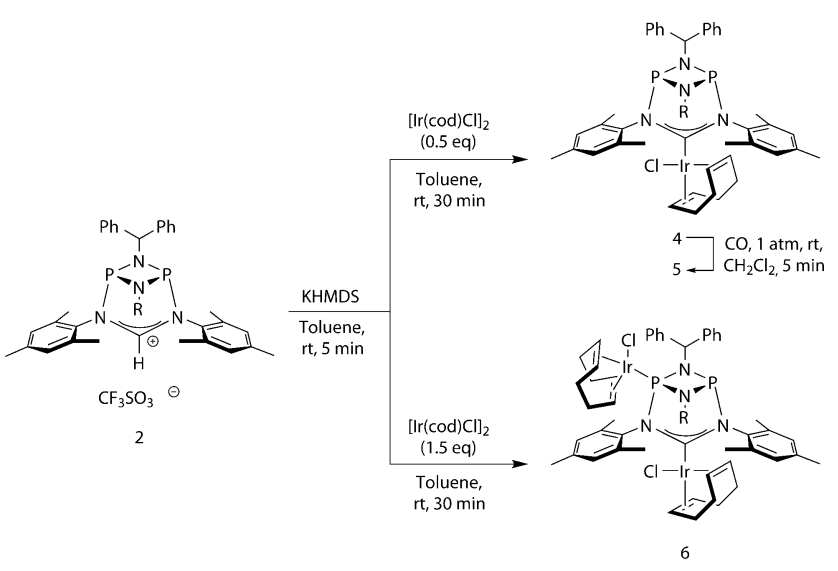

Scheme 2 Metalation of carbene 3. 

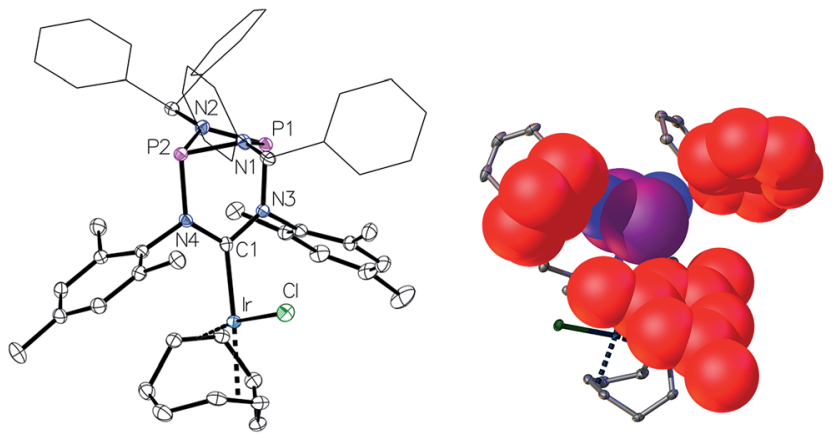

Fig. 4 Left: molecular structure of 4, thermal ellipsoids set at the 50\% probability level. $\mathrm{H}$-atoms have been omitted for clarity. Phenyl rings of the benzhydryl substituents are drawn as wireframes. Selected bond lengths $[\AA \AA]$ and angles $\left[{ }^{\circ}\right]$ : Ir-C1 2.040(2), P1-N3 1.7658(19), N3-C1 1.372(3), N3-C1-N4 114.06(19). Right: space-filling representation of one of the $C_{3}$-symmetric binding pockets. Phenyl and mesityl rings marking the boundary of the cavity are highlighted in red.

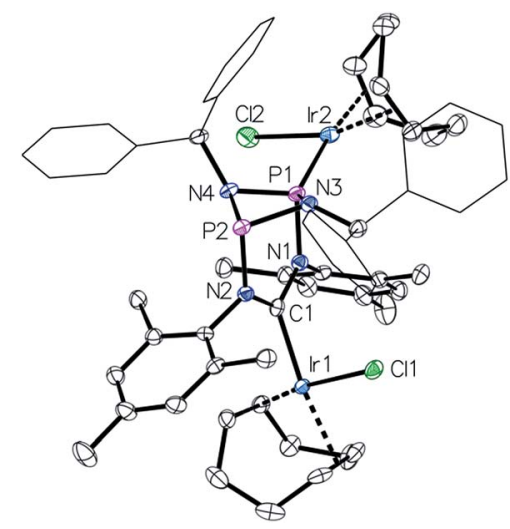

Fig. 5 Molecular structure of 6 , thermal ellipsoids set at the $50 \%$ probability level. $\mathrm{H}$-atoms have been omitted for clarity. Phenyl rings of the benzhydryl substituents are drawn as wireframes. Selected bond lengths $[\AA \AA]$ and angles $\left[^{\circ}\right]$ : Ir1-C1 2.046(3), Ir2-P1 2.2359(8), P1-N1 1.756(3), N1-C1 1.385(4), Ir2-P1-P2 158.50(4), N2-C1-N1 114.9(3).

state structure of the product 6 reveals that the coordination of the second iridium fragment by one phosphorus lone pair induces a slight internal rearrangement within the core structure, thus effectively sterically-blocking the second phosphorus coordination site (Fig. 5). Since 6 could only be isolated in pure form in the solid state and ${ }^{31} \mathrm{P}$ NMR spectra showed a mixture of 4 and $\mathbf{6}$ in solution, a VT NMR study was conducted to probe the coordination behavior of the $\mathrm{P}_{2} \mathrm{~N}_{2}$ phosphorus atoms. Crystals of complex 6 were dissolved in THF and the resulting equilibrium was studied in the temperature range -30 to $50{ }^{\circ} \mathrm{C}$. A labile P-Ir bond and an entropically driven reversible dissociation process was found $\left(\mathbf{6} \rightarrow \mathbf{4}+1 / 2[\operatorname{Ir}(\operatorname{cod}) \mathrm{Cl}]_{2}, \Delta H=+30 \mathrm{~kJ}\right.$ $\left.\mathrm{mol}^{-1}, \Delta S=+77 \mathrm{~J} \mathrm{~mol}^{-1}\right)$.

Moreover, to preclude electronic effects as the cause for the bismetalation product $\mathbf{6}$, we exchanged the square-planar [Ir]-precursor for a sterically less demanding linear gold(I) fragment. By a procedure analogous to the preparation of 6 the heterotrimetallic complex 7 was obtained (Fig. 6). Consequently, the ${ }^{13} \mathrm{C}$ NMR shift of the carbene carbon atom
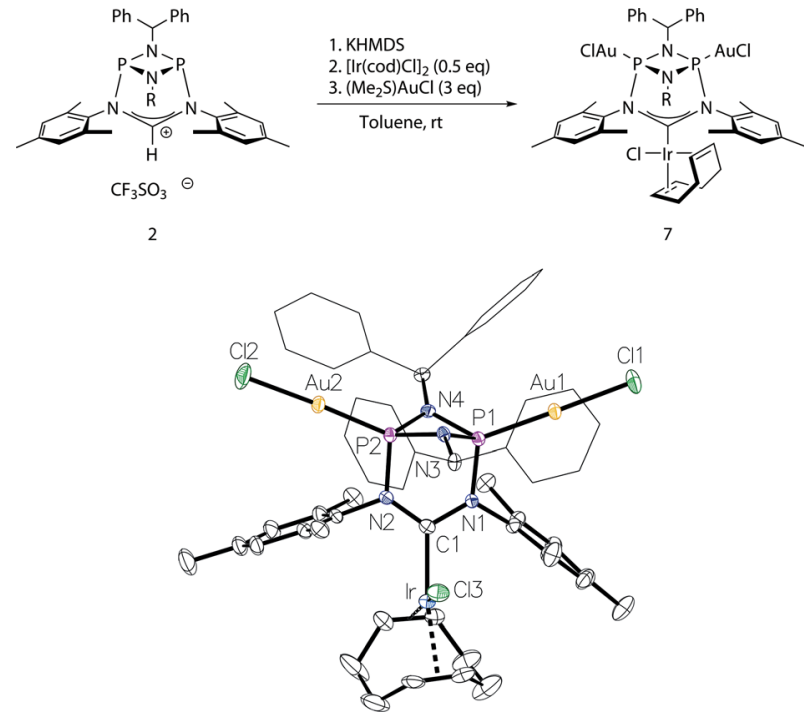

Fig. 6 Top: access to the trimetallic complex 7. Bottom: molecular structure of 7 , thermal ellipsoids set at the $50 \%$ probability level. $\mathrm{H}$ atoms have been omitted for clarity. Phenyl rings of the benzhydryl substituents are drawn as wireframes. Selected bond lengths $[\AA]]$ and angles [ ${ }^{\circ}$ ]: Au1-P1 2.1839(10), Ir-C1 2.020(4), P1-N1 1.719(4), P1-N3 1.712(4), N1-C1 1.390(5), N2-C1-N1 115.3(4).

of $\delta=234 \mathrm{ppm}\left(\mathrm{t}, J_{\mathrm{C}-\mathrm{P}}=4.5 \mathrm{~Hz}\right)$ corroborates coordination of the $[\mathrm{Ir}(\mathrm{cod}) \mathrm{Cl}]$ fragment and the single ${ }^{31} \mathrm{P}$ NMR resonance of $128 \mathrm{ppm}$ establishes metalation of both phosphorus atoms. Details of the molecular structure have also been established by X-ray diffraction (Fig. 6). Complex 7 was also converted to its corresponding carbonyl complex by the previously mentioned procedure for compound $\mathbf{5}$. However, significant decomposition precluded its isolation in a pure state. The carbonyl complex exhibits a ${ }^{31} \mathrm{P}$ NMR resonance at $131 \mathrm{ppm}$ and the IR spectrum shows two CO stretching vibrations at $2071 \mathrm{~cm}^{-1}$ and $1986 \mathrm{~cm}^{-1}\left(\nu_{\mathrm{av}}(\mathrm{CO})=2029 \mathrm{~cm}^{-1}\right.$; TEP $=$ $2054 \mathrm{~cm}^{-1}$ ).

Finally, the steric properties of the ligand system were analyzed. The extended heteroatomic backbone leads to a more confined metal coordination site compared to the standard SIMes NHC (Fig. 7). This effect is accomplished by a smaller angle between the mesityl substituents and the presence of the bulky $\mathrm{P}_{2} \mathrm{~N}_{2}$ substituents. Moreover the CPK model demonstrates the close spatial proximity of the benzhydryl phenyl groups to the iridium binding pocket, thus effectively shielding the backside of the NHC.

To obtain a quantitative measure for the steric congestion of the metal centre we have determined buried volumes $\% V_{\text {bur }}$ of all isolated complexes for the NHC and the phosphorus donor sites (Table 1). ${ }^{27}$ As expected, all phosphazane-NHC complexes reported in this work feature increased buried volumes compared to the SIMes reference system. Remarkably, the steric properties of the NHC-metal unit are unaffected by the coordination of metal fragments to the $\mathrm{P}_{2} \mathrm{~N}_{2}$ backbone. This offers a convenient way to modify the NHC donor strength independently from the sterics. 

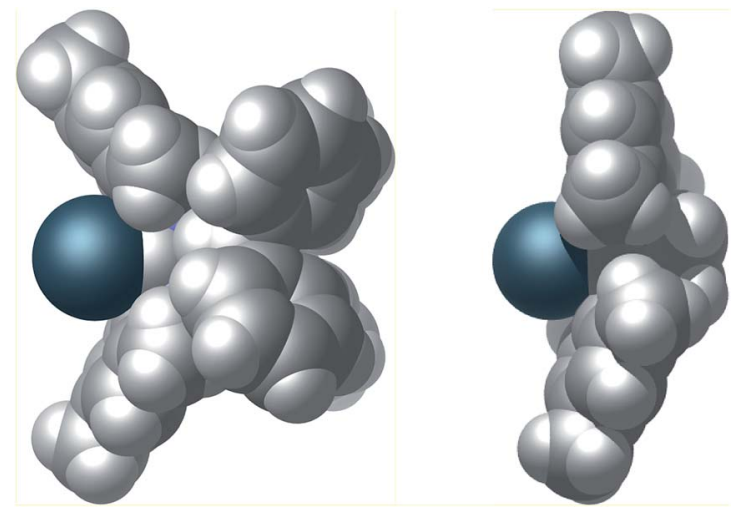

Fig. 7 CPK model of the van der Waals surface of complex 4 (left) and, for comparison complex SIMes $\cdot[\mid \mathrm{r}(\mathrm{cod}) \mathrm{Cl}]$ (right). ${ }^{26}$ Cyclooctadiene and chlorido ligands have been omitted for clarity.

Table 1 Calculated buried volume $\% V_{\text {bur }}$ of the reported $\mathrm{P}_{2} \mathrm{~N}_{2}$ cages $^{27}$

\begin{tabular}{llll}
\hline Compound & $\% V_{\text {bur }}-\mathrm{NHC}$ & $\% V_{\text {bur }}-\mathrm{P}_{(1)}$ & $\% V_{\text {bur }}-\mathrm{P}_{(2)}$ \\
\hline $\mathbf{2}$ & 45.6 & 55.3 & 52.9 \\
$\mathbf{4}$ & 36.7 & 52.7 & 57.7 \\
$\mathbf{5}$ & 38.8 & 56.9 & 49.9 \\
$\mathbf{6}$ & 37.3 & $41.9^{a}$ & 60.6 \\
7 & 36.7 & 55.4 & 57.6
\end{tabular}

${ }^{a}$ Phosphorus atom is coordinated to [ $\left.\operatorname{Ir}(\operatorname{cod}) \mathrm{Cl}\right]$.

\section{Conclusion}

We have established a cyclic $\mathrm{P}_{2} \mathrm{~N}_{2}$ unit as a stable "inorganic" carbene backbone moiety within a new type of polytopical hybrid phosph(III)azane/NHC system. The new ligand is structurally rigid and a strong $\sigma$-donor. Importantly, the essentially flat spatial arrangement of conventional NHCs, often described as fan-, wedge- or fence-like, is extended into the third dimension in our new system, in which the orthogonal disposition of the $\mathrm{P}_{2} \mathrm{~N}_{2}$ ring unit provides a unique architecture for tuning the steric and spatial properties of the carbene binding site. The ability of these new ligands to coordinate metal centres using their P-atoms provides a further means by which the steric and electronic character of the carbene fragment can be modified. In addition, the simple "click" approach may allow a broad range of hybrid NHCs of this type to be prepared, with (for example) the future potential for readily introduced chiral functionality at the phosphazane-N atom. Further studies in this area are ongoing.

\section{Acknowledgements}

We gratefully acknowledge the award of a Ph.D. grant to T.R. from the Landesgraduiertenförderung (LGF Funding Program of the state of Baden-Württemberg), the award of the national scholarship "Deutschlandstipendium" to V.V., the University of Heidelberg for generous funding, the EU (Erasmus-Program for V.V., C.G.M.B.) and the ERC-Advanced Investigator Grant (C.G.M.B., D.S.W.).

\section{Notes and references}

1 Monographs: (a) S. P. Nolan, N-Heterocyclic Carbenes: Effective Tools for Organometallic Synthesis, Wiley-VCH, 2014; (b) R. A. Moss and M. P. Doyle, Contemporary Carbene Chemistry, Wiley, Hoboken, 2014; (c) S. DíezGonzález, N-Heterocyclic Carbenes: From Laboratory Curiosities to Efficient Synthetic Tools, Royal Society of Chemistry, 2011; (d) C. S. J. Cazin, N-Heterocyclic Carbenes in Transition Metal Catalysis and Organocatalysis, Springer, 2011, vol. 32; (e) O. Kühl, Functionalised N-Heterocyclic Carbene Complexes, Wiley, 2010; (f) F. Glorius, $N$ Heterocyclic Carbenes in Transition Metal Catalysis, Springer, vol. 21, 2007; (g) S. P. Nolan, N-Heterocyclic Carbenes in Synthesis, Wiley-VCH, 2006; (h) G. Bertrand, Carbene Chemistry: From Fleeting Intermediates to Powerful Reagents, Marcel Dekker Inc., 2002; (i) E. Kolychev, E. Theuergarten and M. Tamm, in Frustrated Lewis Pairs II, ed. G. Erker and D. W. Stephan, Springer, Berlin, Heidelberg, 2013, vol. 334, pp. 121-155.

2 General review articles: (a) M. N. Hopkinson, C. Richter, M. Schedler and F. Glorius, Nature, 2014, 510, 485-496; (b) D. Bourissou, O. Guerret, F. P. Gabbaï and G. Bertrand, Chem. Rev., 2000, 100, 39-91; (c) A. J. Arduengo III, Acc. Chem. Res., 1999, 32, 913-921.

3 Coordination chemistry review articles: (a) F. E. Hahn and M. C. Jahnke, Angew. Chem., Int. Ed., 2008, 47, 3122-3172; (b) D. Martin, M. Soleilhavoup and G. Bertrand, Chem. Sci., 2011, 2, 389-399; (c) J. C. Y. Lin, R. T. W. Huang, C. S. Lee, A. Bhattacharyya, W. S. Hwang and I. J. B. Lin, Chem. Rev., 2009, 109, 3561-3598; (d) Y. Wang and G. H. Robinson, Dalton Trans., 2012, 41, 337-345; (e) P. de Frémont, N. Marion and S. P. Nolan, Coord. Chem. Rev., 2009, 253, 862-892.

4 Catalysis review articles: (a) S. Díez-González, N. Marion and S. P. Nolan, Chem. Rev., 2009, 109, 3612-3676; (b) W. A. Herrmann, Angew. Chem., Int. Ed., 2002, 41, 12901309; (c) V. César, S. Bellemin-Laponnaz and L. H. Gade, Chem. Soc. Rev., 2004, 33, 619-636; (d) F. Wang, L.-j. Liu, W. Wang, S. Li and M. Shi, Coord. Chem. Rev., 2012, 256, 804-853.

5 Organocatalysis review articles: (a) D. Enders, O. Niemeier and A. Henseler, Chem. Rev., 2007, 107, 5606-5655; (b) X. Bugaut and F. Glorius, Chem. Soc. Rev., 2012, 41, 35113522.

6 Other review articles: (a) W. Liu and R. Gust, Chem. Soc. Rev., 2013, 42, 755-773; (b) M. Fèvre, J. Pinaud, Y. Gnanou, J. Vignolle and D. Taton, Chem. Soc. Rev., 2013, 42, 21422172; (c) L. Mercs and M. Albrecht, Chem. Soc. Rev., 2010, 39, 1903-1912; (d) R. Visbal and M. C. Gimeno, Chem. Soc. Rev., 2014, 43, 3551-3574; (e) K. M. Hindi, M. J. Panzner, C. A. Tessier, C. L. Cannon and W. J. Youngs, Chem. Rev., 2009, 109, 3859-3884; $(f)$ A. Gautier and F. Cisnetti, Metallomics, 2012, 4, 23-32.

7 (a) D. J. Nelson and S. P. Nolan, Chem. Soc. Rev., 2013, 42, 6723-6753; (b) T. Dröge and F. Glorius, Angew. Chem., Int. 
Ed., 2010, 49, 6940-6952; (c) S. Díez-González and S. P. Nolan, Coord. Chem. Rev., 2007, 251, 874-883; (d) O. Kühl, Coord. Chem. Rev., 2005, 249, 693-704.

8 (a) D. Martin, Y. Canac, V. Lavallo and G. Bertrand, J. Am. Chem. Soc., 2014, 136, 5023-5030; (b) C. C. Scarborough, M. J. W. Grady, I. A. Guzei, B. A. Gandhi, E. E. Bunel and S. S. Stahl, Angew. Chem., Int. Ed., 2005, 44, 5269-5272; (c) W. Y. Lu, K. J. Cavell, J. S. Wixey and B. Kariuki, Organometallics, 2011, 30, 5649-5655; (d) M. Iglesias, D. J. Beetstra, B. Kariuki, K. J. Cavell, A. Dervisi and I. A. Fallis, Eur. J. Inorg. Chem., 2009, 1913-1919.

9 (a) M. Melaimi, M. Soleilhavoup and G. Bertrand, Angew. Chem., Int. Ed., 2010, 49, 8810-8849; (b) V. Lavallo, Y. Canac, C. Präsang, B. Donnadieu and G. Bertrand, Angew. Chem., Int. Ed., 2005, 44, 5705-5709; (c) M. Soleilhavoup and G. Bertrand, Acc. Chem. Res., 2015, 48, 256-266.

10 (a) R. H. Crabtree, Coord. Chem. Rev., 2013, 257, 755-766; (b) O. Schuster, L. Yang, H. G. Raubenheimer and M. Albrecht, Chem. Rev., 2009, 109, 3445-3478; (c) P. L. Arnold and S. Pearson, Coord. Chem. Rev., 2007, 251, 596-609.

11 V. P. Boyarskiy, K. V. Luzyanin and V. Y. Kukushkin, Coord. Chem. Rev., 2012, 256, 2029-2056.

12 D. Martin, N. Lassauque, B. Donnadieu and G. Bertrand, Angew. Chem., Int. Ed., 2012, 51, 6172-6175.

13 (a) A. Igau, H. Grützmacher, A. Baceiredo and G. Bertrand, J. Am. Chem. Soc., 1988, 110, 6463-6466; (b) G. Bertrand and R. Reed, Coord. Chem. Rev., 1994, 137, 323-355.

14 For a selection see: (a) D. M. Khramov, E. L. Rosen, V. M. Lynch and C. W. Bielawski, Angew. Chem., Int. Ed., 2008, 47, 2267-2270; (b) E. L. Rosen, C. D. Varnado, A. G. Tennyson, D. M. Khramov, J. W. Kamplain, D. H. Sung, P. T. Cresswell, V. M. Lynch and C. W. Bielawski, Organometallics, 2009, 28, 6695-6706; (c) A. G. Tennyson, V. M. Lynch and C. W. Bielawski, J. Am. Chem. Soc., 2010, 132, 9420-9429; (d) B. M. Neilson and C. W. Bielawski, ACS Catal., 2013, 3, 1874-1885.

15 A. Fürstner, M. Alcarazo, H. Krause and C. W. Lehmann, J. Am. Chem. Soc., 2007, 129, 12676-12677.

16 (a) E. Despagnet-Ayoub and R. H. Grubbs, J. Am. Chem. Soc., 2004, 126, 10198-10199; (b) K. E. Krahulic, G. D. Enright, M. Parvez and R. Roesler, J. Am. Chem. Soc., 2005, 127, 4142-4143; (c) C. Präsang, B. Donnadieu and G. Bertrand, J. Am. Chem. Soc., 2005, 127, 10182-10183; (d) Y. Ishida, B. Donnadieu and G. Bertrand, Proc. Natl. Acad. Sci. U. S. A., 2006, 103, 13585-13588; (e) T. D. Forster, K. E. Krahulic, H. M. Tuononen, R. McDonald, M. Parvez and R. Roesler, Angew. Chem., Int. Ed., 2006, 45, 6356-6359; (f) J. Ruiz, L. García, B. F. Perandones and M. Vivanco, Angew. Chem., Int. Ed., 2011, 50, 3010-3012; (g) A. J. Arduengo III, D. Tapu and W. J. Marshall, Angew. Chem., Int. Ed., 2005, 44, 72407244; (h) A. Kausamo, H. M. Tuononen, K. E. Krahulic and R. Roesler, Inorg. Chem., 2008, 47, 1145-1154; (i) A. ElHellani and V. Lavallo, Angew. Chem., Int. Ed., 2014, 53, 4489-4493; (j) M. J. Asay, S. P. Fisher, S. E. Lee, F. S. Tham, D. Borchardt and V. Lavallo, Chem. Commun., 2015, DOI: 10.1039/c4cc08267b.
17 D. Katayev, Y.-X. Jia, A. K. Sharma, D. Banerjee, C. Besnard, R. B. Sunoj and E. P. Kündig, Chem.-Eur. J., 2013, 19, 1191611927 and references therein.

18 (a) R. H. Crabtree, J. Organomet. Chem., 2005, 690, 54515457; (b) P. W. N. M. van Leeuwen and P. C. J. Kamer, Phosphorus Ligand Effects in Homogeneous Catalysis and Rational Catalyst Design, in Phosphorus(III) Ligands in Homogeneous Catalysis: Design and Synthesis, John Wiley \& Sons, Ltd, Chichester, UK, 2012. See also ref. 1-6 for a broader overview.

19 T. Roth, H. Wadepohl, D. S. Wright and L. H. Gade, Chem.Eur. J., 2013, 19, 13823-13837.

20 For a review of polytopical NHC ligands see M. Poyatos, J. A. Mata and E. Peris, Chem. Rev., 2009, 109, 3677-3707. For a selection of hybrid ambidentate NHC ligands see $(a)$ D. M. Khramov, A. J. Boydston and C. W. Bielawski, Angew. Chem., Int. Ed., 2006, 45, 6186-6189; (b) A. Zanardi, J. A. Mata and E. Peris, J. Am. Chem. Soc., 2009, 131, 14531-14537; (c) N. Vujkovic, V. César, N. Lugan and G. Lavigne, Chem.-Eur. J., 2011, 17, 13151-13155; (d) D. Mendoza-Espinosa, B. Donnadieu and G. Bertrand, Chem.-Asian J., 2011, 6, 1099-1103; (e) J. Ruiz and A. F. Mesa, Chem.-Eur. J., 2012, 18, 4485-4488; (f) P. L. Arnold and S. T. Liddle, Organometallics, 2006, 25, 1485-1491; V. César, V. Mallardo, A. Nano, G. Dahm, N. Lugan, G. Lavigne and S. Bellemin-Laponnaz, Chem. Commun., 2015, DOI: 10.1039/c4cc08641d; and references therein.

21 L. Benhamou, E. Chardon, G. Lavigne, S. Bellemin-Laponnaz and V. César, Chem. Rev., 2011, 111, 2705-2733.

22 No signs of decomposition were observed upon heating a toluene solution of 5 to $100{ }^{\circ} \mathrm{C}$.

23 C. A. Tolman, Chem. Rev., 1977, 77, 313-348.

24 The expression TEP $=0.847 \nu_{\text {av }}(\mathrm{CO})+336 \mathrm{~cm}^{-1}$ was used. (See ref. (7a)).

25 For CV and IR data of a range of iridium NHC complexes see (a) S. Leuthäußer, D. Schwarz and H. Plenio, Chem.-Eur. J., 2007, 13, 7195-7203; (b) R. A. Kelly III, H. Clavier, S. Giudice, N. M. Scott, E. D. Stevens, J. Bordner, I. Samardjiev, C. D. Hoff, L. Cavallo and S. P. Nolan, Organometallics, 2008, 27, 202-210; (c) S. Wolf and H. Plenio, J. Organomet. Chem., 2009, 694, 1487-1492; (d) A. R. Chianese, X. Li, M. C. Janzen, J. W. Faller and R. H. Crabtree, Organometallics, 2003, 22, 1663-1667.

26 Crystal structure of SIMes · $[\operatorname{Ir}(\operatorname{cod}) \mathrm{Cl}]$ taken from R. A. Kelly III, H. Clavier, S. Giudice, N. M. Scott, E. D. Stevens, J. Bordner, I. Samardjiev, C. D. Hoff, L. Cavallo and S. P. Nolan, Organometallics, 2008, 27, 202.

27 The calculations of the buried volume $\% V_{\text {bur }}$ were carried out using the SambVca Web Application (https:// www.molnac.unisa.it/OMtools/sambvca.php) by Cavallo and coworkers: A. Poater, B. Cosenza, A. Correa, S. Giudice, F. Ragone, V. Scarano and L. Cavallo, Eur. J. Inorg. Chem., 2009, 13, 1759-1777. Parameters used: sphere radius $3.5 \AA$, distance from the center of the sphere: 2.10 $\AA$, mesh spacing: $0.05 \AA, \mathrm{H}$ atoms were not included, Bondi radii were scaled by 1.17 . 